\title{
Mental Health Stigma in the Muslim Community
}

\author{
Ayse Ciftci \\ Purdue University
}

\author{
Nev Jones and Patrick W. Corrigan \\ Illinois Institute of Technology
}

\begin{abstract}
Mental illness stigma continues to be a major barrier for individuals with mental illness. In this paper, we define constructs that comprise stigma (e.g., attitudes, stereotypes, prejudice, discrimination), discuss the harmful effects (e.g., label avoidance, public stigma, self-stigma) and present factors that may influence them (e.g., concealability). In order to better understand mental health stigma in Muslim community, we focus on intersectional stigma and present literature on the complex relationships among race/ethnicity, gender, class, religion, and health status among Muslims. In addition, we include literature highlighting culturally specific presentations of symptoms and mental health problems. Finally, we offer suggestions for future stigma research in Muslim communities.
\end{abstract}

And We will surely test you with something of fear and hunger and a loss of wealth and lives and fruits, but give good tidings to the patient (Surat AiBaqarah 2:155)

Although mental health care has improved significantly over the last decades, many people still choose not to seek treatment or quit prematurely. A number of possible factors contribute to these disparities with stigma being perhaps the most significant. Stigma hurts individuals with mental illness and their communities, creating injustices and sometimes devastating consequences. In this paper, we discuss mental illness stigma and its related constructs, describe the 
current state of understanding mental illness stigma in Islam, and summarize critical considerations to address stigma in this community.

Stigma is defined as "the situation of the individual who is disqualified from full social acceptance" (Goffman, 1963, p. 9). In this paper, we distinguish label avoidance from public stigma. Label avoidance refers to instances in which individuals choose to not seek help for mental health problems in order to avoid negative labels (Corrigan, Roe, \& Tsang, 2011). In order to avoid psychiatric labels, individuals may choose to not associate themselves with mental health clinic or professionals -- avoiding diagnosis by avoiding mental health care. Public stigma is the prejudice and discrimination that blocks individuals' access to employment, educational opportunities, health care, and housing. Public stigma occurs when members of the general public endorse stereotypes about mental illness and act on the basis of these stereotypes.

In order to unpack the stigma process, it is helpful to differentiate key terms that comprise the stigma construct: attitudes, stereotypes, prejudice, and discrimination (Corrigan, Roe, \& Tsang, 2011). We form attitudes based on seemingly factual views of the world and our values and emotional reactions to these views. Attitudes can be positive or negative. Stereotypes are attitudes made about individuals based on their assignment to a particular group or category. Stereotypes per se rely on generalizations that are often inaccurate or misleading when applied to particular cases. Prejudice refers to negative affective attitudes toward particular groups and implies agreement with derogatory or pejorative stereotypes. An individual walking by men wearing turbans, for example, might not only assume that they are terrorists (a stereotype) but also feel anger and fear toward them because of their presumed dangerousness (prejudice).

Discrimination is the behavioral component of stigma and occurs when people act on the basis of prejudiced attitudes or beliefs. For example, individuals who believe that Muslim men are 'dangerous' and untrustworthy might avoid neighborhoods in which Muslim families live, or report these men to airport police for "suspicious" activities. Behavioral discrimination might also occur in subtle forms such as choosing not to sit next to an individual wearing a turban on the train.

Both label avoidance and self-stigma are frequently framed as consequences of public stigma (Corrigan et al., 2001). Self-stigma occurs when individuals belonging to a stigmatized group internalize public prejudice and direct it toward themselves. The self-stigma process can be broken down into component parts, including awareness (e.g., are individuals aware of the stereotypes related to the mental illness?), agreement (e.g., do they agree with the stereotypes?), application (e.g., do they apply these stereotypes to themselves?), and harm (e.g., is this stereotyping harming their self-esteem or self-efficacy to use coping skills to fight stigma's effect?; Corrigan, Larson, \& Kuwabara, 2009). One 
of the most significant harms resulting from self-stigma is the foreclosure of important life pursuits by individuals who come to believe they should not pursue goals that society thinks such individuals cannot succeed in (Corrigan, Larson, \& Rusch, 2009).

\section{Factors that Influence or Moderate Stigma}

Jones and colleagues (1984) propose that stigma is moderated by six factors: concealability, course, disruptiveness, aesthetic qualities, origin, and peril. Concealability refers to the relative apparency of a stigmatizing attribute. Skin color is often visible, whereas mental illness can often be concealed. While highly visible stigmas lead to immediate discrimination, concealable stigmas have other negative consequences. Although a stigma such as mental illness can be hidden in some circumstances, management of information about itwho to disclose to, who not to, how to keep records hidden-may lead to high levels of social stress and strained social interactions (Beatty \& Kirby, 2004; Clair, Beatty, \& MacLean, 2005; Joachim \& Acorn, 2000). Discrimination stemming from visible stigmas may be easier to identify and legally prosecute than discrimination based on invisible attributes (Stefan, 2000). Of the other dimensions articulated by Jones and colleagues, course and peril have emerged as important influences on the degree of stigma and its negative behavioral consequences (Jorm \& Griffiths, 2008; Keller, 2005; Link et al., 1999). In recent years, a number of researchers have also begun to explore the influence of different explanatory models or causal beliefs regarding the origins and nature of mental illness (Phelan, 2005; Rusch et al., 2010; Schomerus et al., 2012; Schomerus, Matschinger, \& Angermeyer, 2013).

With respect to self-stigma, Corrigan and Watson (2002) suggest that group identification and perceived legitimacy of public stigma influence selfstigma. This leads to a paradox: individuals who are aware of public stigma may view these attitudes as legitimate (resulting in low self-esteem) or not legitimate (resulting in intact self-esteem), and react with shame, indifference, or righteous anger, depending on their level of identification with their in-group. Perceptions of legitimacy is influenced by several factors including negative social feedback and personal values that may protect against self-stigma. Rusch and colleagues $(2009,2010)$ examined the influence of in-group perception, perceived legitimacy of discrimination, responses to stigma, and causal attributions. Entitativity is "the perception of the in-group as a coherent unit" (Rusch et al., 2009, p. 320). For example, individuals may have low entitativity about the 'group of people' waiting in a grocery check-out line versus those who attend their mosque. Findings suggested that individuals with high group value (higher group identification and entitativity) and lower perceived legiti- 
macy are more resilient to stigma. Group identification can be a critical issue especially dealing with stigma in minority or more collectivist communities.

\section{Double Stigma and Intersectionality}

Stigma impacts individuals of color and minority cultures. Studies conducted within the United States suggest that the experience of mental illness stigma can be more complicated for those from racial and ethnic minority groups. Gary (2005) examined four ethnic groups in the United States (i.e., African Americans, American Indians and Alaska Natives, Asian Americans, and Hispanic Americans) and proposed the concept of "double stigma," stemming from prejudice and discrimination occasioned by individual's racial identity and their mental illness. Intersectionality describes the complex relationships between different identities (e.g., race, gender, sexual orientation, class, and disability) and forms of oppression. Effects of interlocking identity axes must be considered simultaneously (Cole, 2009; Collins, 2000, 2007; Hancock, 2007). Oppression associated with race, economic status, disability, and gender operate as an intersecting system, not as unrelated instances of oppression. To use a classic example, middle-class white women are often viewed as relatively asexual pillars of family values, while poor African American women are seen as sexually "promiscuous" (Collins, 2000). An intersectionalist framework proposes that the process and effects of the stigmatization of, for example, a working-class Muslim woman with depression will differ from that of a middle-class White woman with depression not only in degree (i.e., 'more' or additive stigma), but in kind (i.e., qualitatively different stigma with fundamentally different effects on the stigmatized individual).

Although the literature on stigma and intersectionality remains small, existing studies underscore the importance of work in this area. On the experimental side, Wirth and Bodenhausen (2007) found that participants reading case studies of men and women with either gender-typical (e.g., women with depression) or gender-atypical (e.g., men with depression) psychiatric conditions reacted differently. When cases were gender-typical, participants expressed less sympathy and decreased willingness to provide help or support, relative to cases perceived as gender-atypical. In the context of applied scholarship, Collins and colleagues (Collins et al., 2008; Collins, von Unger, \& Armbrister, 2008) have unpacked relationships between gender, ethnicity, serious mental illness, and HIV/AIDS risk behaviors. They found complex interplay among identities (particularly gender and mental illness), the social norms affecting these identities, and sexual risk-taking. Study participants, for example, described culturally specific conflicts between mental illness stigma and Latino gender norms that undermined power and leverage in sexual relationships, 
ultimately leading to higher levels of unprotected sex and greater exposure to HIV/AIDS.

Several studies have focused on differences between racial minorities with respect to mental illness stigma with trends suggesting different patterns of stigma based on sex, race, and racial identity (Corrigan \& Watson, 2007; Loya, Reddy, \& Hisnhaw 2010; Rao, Feinglass, \& Corrigan, 2007). Specifically, some minorities, including African Americans and Asian Americans, have higher levels of mental illness stigma compared to the "majority" individuals (Abdullah \& Brown, 2011; Anglin, Link, \& Phelan, 2006). However, this trend is not clear for all groups. For example, in a study of 357 students $(20 \%$ African American, 28\% Latino, 8\% Asian), Rao, Feinglass and Corrigan (2007) found that African Americans and Asians perceived people with mental illness as more dangerous and preferred segregation than Caucasians, while Latinos perceived people with mental illness as less dangerous and preferred less segregation than Caucasians. In the same study, Asian students also showed higher stigma change following a targeted intervention. Another study found that South Asian students reported significantly less positive public attitudes toward help-seeking than Caucasians (Loya, Reddy \& Hisnhaw, 2010). After including personal stigma variables as mediators in their model, however, the effect of ethnicity on help-seeking attitudes was significantly reduced. The mediational analysis suggested that for South Asian students, personal stigma, not perceived public stigma, accounted for $32 \%$ of the differences in attitudes toward help-seeking.

These studies suggest that demographic differences impact ways in which members of ethnic and cultural minority groups stigmatize mental illness in the US. Differences in stigma level and content have also been identified stemming from class and educational attainment (Phelan, Bromet, \& Link, 1998), specific religious beliefs (Wesselmann \& Graziano, 2010) and gender (Corrigan \& Watson, 2007). The complex interactions between race/ethnicity, gender, class, religion, and health status have nevertheless gone largely unexplored, suggesting a need for more sophisticated intersectional analyses.

\section{Mental Illness Stigma outside of the United States}

Mental illness stigma is a significant problem not only in the Unites States, but around the world (Crabb et al., 2012; Fung, Tsang, Corrigan, Lam, \& Cheng, 2007; Lauber \& Rössler, 2007; Ng, 1997; Tal, Roe, \& Corrigan, 2007). However, while stigma as a broad construct can be identified across cultures, influences, dimensions and consequences vary substantially within local context (Yang et al., 2007). In Chinese culture, for instance, where individuals are seen as links in an intergenerational kinship structure whose central responsibility is not to 
themselves but to family and ancestors, mental illness 'contaminates' not only the individual but also the extended family (Yang \& Pearson, 2002). Chinese persons with mental illness may also be more susceptible to self-stigma, due to the more immediate and reflexive influence of the collective on personal beliefs (Fung, Tsang, Corrigan, Lam, \& Cheng, 2007). In Egypt, on the other hand, where problems tend to be understood in intersubjective rather than intrapsychic terms, less blame is placed on the individual with mental illness; mental illness in a more collective sense is nevertheless seen as a significant threat to social order, as exemplified by the physical isolation and segregation of psychiatric facilities (Coker, 2005).

Cultural differences also have significant implications with respect to caregiver stigma and burden. Comparing India and the United States, for instance, Marrow and Luhrmann (2012) describe how perceptions of family honor, shame, and moral responsibility, access to psychiatric services, and cultural acceptance of biomedical approaches to mental health treatment, combine to lead Indian families to hide family members with severe psychosis within their homes (taking on the majority of caregiver burdens), and American families to abandon them to institutions or on the streets. Chinese families may also keep family member's illness a secret in order to save face (Mak \& Cheung, 2008).

Consistent with these findings, Ciftci (1999) observed a strong sense of family shame at a rehabilitation center in Turkey while working with families and children with mental illness. In some cases, shame was so extreme it led to locking children in the house and not "coming out" in public. Most frequently, fathers would blame mothers for giving birth to a child with mental illness. It was extremely critical to incorporate the support from extended family and other elders (e.g., religious) in the community to make changes.

\section{Health, Mental Health, and Islam}

The global Muslim population is estimated to be around 1.6 billion persons, which makes up about $23 \%$ of the world's population, with $62 \%$ of Muslims living in Asian-Pacific countries (e.g., Indonesia, Pakistan, India, Bangladesh, Iran, and Turkey), $20 \%$ in the Middle East or North Africa (e.g., Egypt, Yemen, Sudan, Saudi Arabia, Algeria, Syria), 15\% in Sub-Saharan Africa (e.g., Nigeria, Rwanda, Kenya), 3\% in Europe (e.g., France, Belgium, Austria, United Kingdom) and less than 1\% in North America (e.g., United States, Canada). According to Pew Research Center's Forum on Religion and Public Life (2011), this number is expected to increase by about $35 \%$ by 2030 . In the U.S., approximately $32 \%$ of the Muslim population is South Asian, with $26 \%$ Arab, and $20 \%$ African American. 
Although Muslim beliefs and ethnic sub-cultures are heterogeneous, they are often perceived as a monolithic group, negatively stereotyped and subjected to significant interpersonal and structural discrimination (Jamal, 2008; Jasinskaja-Lahti,Liebkind, \& Perhoniemi, 2006; Whidden, 2000). Before discussing mental illness stigma in Muslim communities, and the intersection of religion, culture, and mental illness stigma, we describe cultural definitions of health and mental health within Islam.

There are contextual differences among practices and beliefs about health and illness and important commonalities across Muslim groups. A fundamental tenet of Islam is that there is one God (the Arabic word for God, Allah, is used universally by Muslims, regardless of ethnic group or language of origin) and Allah causes everything including illnesses. According to some religious leaders, illness is one method of connection with God and should not be considered as alien, but "rather ... an event, a mechanism of the body, that is serving to cleanse, purify, and balance us on the physical, emotional, mental, and spiritual planes." (Rasool, 2000, p. 1479). This core belief is reflected in multiple studies on the perspectives of Muslim community members extending to both physical and mental illnesses (DeShaw, 2006; Padella et al., 2012; Ypinazar \& Margolis, 2006; Shah, Ayash, Pharaon, \& Gany, 2008). For example, South Asian Muslim women queried about the cause of breast cancer strongly affirmed God's role in determining both who gets sick and who is healed (Johnson et al., 1999). In a focus group of American Muslims examining health attitudes, one participant said "God ... is the ultimate doctor. He is the one who brought down the disease. He is the one that brought down the cure" (Padella et al., 2012, p. 849).

Mental illness may also be perceived as a test or punishment from God (Abu-Ras, Gheith \& Cournos, 2008; Rassoll, 2000). In Muslim culture, belief in kader -- or destiny is strong. While kader may lead to fatalism in some cases (Shah et al., 2008), it also suggests positive acceptance of Allah's will and higher levels of optimism with respect to healing (Hasnain, Shaikh \& Shanawani, 2005; Nabolsi \& Carson, 2011). For instance, illness may be seen as an opportunity to remedy disconnection from Allah or a lack of faith through regular prayer and a sense of self-responsibility (Cinnirella \& Loewenthal, 1999; Padella et al., 2012; Youssef \& Deane, 2006). Imams (traditional spiritual leaders) are often seen as indirect agents of Allah's will and facilitators of the healing process (Abu-Ras et al., 2008; Padela, Killawi, Heisler, Demonner, \& Fetters, 2010; Padella et al., 2012). Imams may also play central roles in shaping family and community attitudes and responses to illness (Padella et al., 2012). For example, Abu-Ras and colleagues (2008) interviewed 22 imams and 102 worshippers from 22 mosques in New York after the September 11 attacks, and found that imams had a critical role in promoting health mental health. In a 
separate study of 62 imams from across the U.S., Ali, Milstein, and Marzuk (2005) found that $95 \%$ reported spending significant time each week providing counseling to their congregants.

Cultural influences on presentation of symptoms and mental health problems also need to be considered. Due to the lesser stigma of physical symptoms as well as cultural idioms revolving around the physical body, mental health problems are often expressed as physical symptoms (Al-Krenawi, 2005; Douki, Zaneb, Nasef, \& Halbreich, 2007; El-Islam, 2008). In parallel, explicit mood symptoms such as hopelessness, self-deprecatory thoughts, and worthlessness, are uncommon; in particular, women ultimately diagnosed with depression frequently first present with "conversion" disorders and no self-recognition of psychological distress or sadness (Al-Krenawi \& Graham, 2000). In addition, normative cultural beliefs in the existence of jinn (evil spirits) may be confused with delusions of possession and control, and may prevent patients and family members from recognizing medical or psychiatric problems (El-Islam, 2008). Significant cultural differences with respect to gender may also put women at especially high risk of diagnosis and treatment of mental health problems in Muslim communities (Al-Krenawi, 2005).

\section{Stigma in Muslim Community}

In this section, we review existing studies with a focus on stigma and then discuss some of the implications of salient cultural differences for future stigma research. In a study on perceptions of and attitudes toward mental illness among both medical students and the general public in Oman, Al-Adawi and colleagues (2002) found that groups believed that mental illness is caused by spirits and rejected genetics as a significant factor. In the same study, both groups endorsed common stereotypes about people with mental illness and affirmed that psychiatric facilities should be segregated from the community. In a separate study examining attitudes toward mental health issues among Pakistani families in the United Kingdom (Tabassum, Macaskill, \& Ahmad, 2000), none of the participants reported that they would consider marriage with a person with mental illness, only half expressed a willingness to socialize with such a person, and less than a quarter reported they would consider a close relationship.

Even when Muslims have positive attitudes toward mental healing, social stigma remains strong. Because of concerns with family social standing, many researchers report that disclosure of mental illness is considered "shameful" (Aloud \& Rathur, 2009; Amer, 2006; Erickson \& Al-Timimi, 2001; Youssef \& Deane, 2006). Seventy-five percent of the mostly Muslim Ethiopian families surveyed by Shibre and colleagues (2001) reported experiencing stigma due to 
a relative with mental illness, with substantial minorities reporting that other community members would be unwilling to marry into their family because of the mental illness (36.5\%). Similarly, Muslim women may avoid sharing personal distress and seeking help from counselors due to fear of negative consequences with respect to marital prospects or their current marriages. In a study with 67 immigrant women who reported experiencing domestic abuse, Abu-Ras (2003) found about 70\% reported shame and 62\% felt embarrassment seeking formal mental health services. Khan's (2006) study involving 459 Muslims in the United States revealed similar gender patterns in stigma and help-seeking. Out of 459 participants, $15.7 \%$ of the participants reported a need for counseling while only $11.1 \%$ reported ever seeking mental health services. These statistics were strongly gendered with Muslim women expressing higher levels of need for mental health services and men more negative attitudes toward help-seeking. On the other hand, family and key stakeholder participants in a qualitative study of a Thai Muslim community rejected the idea that schizophrenia had stigma since the illness was Allah's will (Vanaleesin, Suttharangsee, \& Hatthakit, 2007).

With respect to internalized and self-stigma, a study conducted in Australia with 35 individuals from Arab communities found almost all indicated that stigma was the most significant barrier to accessing mental-health services due to the shame of disclosing personal and family issues to outsiders (Youssef \& Deane, 2006). On the other hand, mean levels of self-stigma as measured by the Self-Stigma of Help-Seeking Scale (SSHS) were found invariant between Turkey and comparator non-Muslim countries (Vogel et al., 2013). One US study also found that self-stigma levels among Muslim students did not significantly mediate their attitudes toward counseling (Soheilian \& Inman, 2009), though these findings may reflect acculturation and/or generational differences that do not hold across American-Muslim communities. Another Midwestern study of Arab Muslim Americans found significant levels of self-reported shame with respect to utilizing formal mental health services (Aloud \& Rathur, 2009). We could not find any existing anti-stigma intervention evaluations or descriptions specifically targeting Muslim individuals.

\section{Key Considerations for Stigma Research within Muslim Communities}

These findings, or lack thereof, underscore the need further research. In addition to research replicating and extending small and/or exclusively qualitative studies, we highlight the need for research sensitive to the following issues: the involvement of families and religious leaders (e.g. imams); double stigma and intersectionality, particularly with respect to race, class, gender, and post-9/11 
discrimination; and culturally specific explanatory models for mental illness and appropriate treatment.

As our literature review attests, families and religious figures are a crucial resource for individuals experiencing mental health problems. In Aloud and Rathur's study (2009) of Muslim Americans, for instance, significantly greater numbers of participants reported willingness to seek help from family members $(21 \%)$ or a religious leader (19\%) than from mental health professionals (11\%). Likewise, participants in a study in the United Arab Emirates found that participants reported greater willingness to seek help from families and religious leaders than formal mental health services (Al-Darmaki, 2003). These findings are consistent with Hamdan's (2009) emphasis on the importance of the collectivist nature of Muslim culture, the importance of integrating religion into treatment, and the perception of mental health illness as a "private family matter." Imams have significant roles in dealing with mental illness in the Muslim community (Abu-Ras, Gheith, \& Cournos, 2008; Youssef \& Deane, 2006). Although imams spend significant time "counseling" congregants, they rarely have formal training in addressing mental health issues.

Consideration of intersectional stigma in the context of Muslim mental health is also critical. In addition to more common intersections of race, class, gender, and health status, Muslim communities, both in the US and abroad, have been shaped by uniquely virulent structural and interpersonal discrimination in the wake of the September 11 attacks (Jamal, 2008). Muslim community members, for example, live in fear of hate crimes, anxiety about the future, threats to their safety, loss of community, and isolation (Abu-Ras \& Abu-Bader, 2008; Rippy \& Newman, 2006). Since the attacks on the Pentagon and World Trade Center and the ensuing wars in Afghanistan and Iraq, there has also been increased media and government scrutiny of the Muslim-American population (Rippy \& Newman, 2006), leading to deep anxiety among MuslimAmericans. In a qualitative study of Muslim American college women wearing the hijab (hair-covering scarf), participants reported fears of both parents and society when deciding whether to visibly identify with the Muslim community (Ciftci, Shawahin, Reid-Marks, \& Ellison 2013). In combination with strongly gendered social and cultural roles, it is thus critically important to investigate contextual factors involving these intersections of identity, stigma, and discrimination. In particular, interventions must take into account the complex additional layers of inter-group conflict, cultural distrust, social isolation, and gendered aspects of community life.

Finally, research within transcultural psychiatry, cross-cultural psychology, and cultural anthropology concerning fundamentally different explanatory models for and conceptualizations of mental illness must be included (Al-Krenawi, 2005; Douki et al., 2007; El-Islam, 2008; Vanaleesin et al., 2007). Hypotheses stemming from predominantly Western research on the links be- 
tween stigma and different causal and treatment beliefs (e.g., Schomerus et al., 2012) must be investigated among diverse Muslim samples. The possibility that cultural normative beliefs may be mislabeled or unidentified due to cultural insensitivity also need to be addressed, particularly insofar as such mislabeling may lead to both the unnecessary stigmatization of those who, in fact, do not have psychiatric problems, and the failure to help individuals who do need it. Further, anti-stigma interventionists must take care to not inadvertently undermine strengths of Muslim attitudes toward mental illness, potentially including less blame placed on patients (at least in some contexts) and greater hope regarding prognosis.

\section{Conclusion: An Urgent Need for Further Research}

The number of Muslim immigrants in the United States and around the world is increasing. Unfortunately, discrimination against this minority group continues to increase as well. Particularly in the wake of the September 11 attacks, and ongoing conflict between Israel and Palestine, some members of the public believe that prejudice against the Muslim community is justified. Disparities in mental health within any community impact society as a whole. An evidence-based approach is needed to understand what should be changed, how this change can be made, and how to best measure it (Corrigan, 2010). Stigma experts emphasize the need for interventions to be local, culturally specific, and carefully targeted (Corrigan, 2011). As our review underscores, these best practices are all the more important in the context of stigma research in Muslim communities.

\section{References}

Abdullah, T., \& Brown, T. L. (2011). Mental illness stigma and ethnocultural beliefs, values, and norms: An integrative review. Clinical Psychology Review, 31, 934-948. http://dx.doi.org/10.1016/j.cpr.2011.05.003

Abu-Ras, W. \& Abu-Bader, S. H. (2008). The impact of the September 11, 2001 Attacks on the well-being of Arab Americans in New York City. Journal of Muslim Mental Health, 3, 217-239. http://dx.doi.org/10.1080/15564900802487634

Abu-Ras, W. (2003). Barriers to services for Arab immigrant battered women in a Detroit suburb. Social Work Research and Evaluation, 3(4), 49-66.

Abu-Ras, W., Gheith, A., \& Cournos, F. (2008). The imam's role in mental health promotion: A study at 22 mosques in New York City's Muslim Community. Journal of Muslim Mental Health, 3, 155-176. http://dx.doi.org/10.1080/15564900802487576

Al-Adawi, S., Dorvlo, A. S., Al-Ismaily, S. S., \& et al. (2002). Perception of and attitude towards mental illness in Oman. The International Journal of Social Psychiatry, 48, 305-317. http://dx.doi.org/10.1177/002076402128783334

Al-Darmaki, F. R. (2003). Attitudes towards seeking professional psychological help: 
What really counts for United Arab Emirates University students? Social Behavior and Personality, 31, 497-508. http://dx.doi.org/10.2224/sbp.2003.31.5.497

Ali, O. M., Milstein, G., \& Marzuk, P. M. (2005). The imam's role in meeting the counseling needs of Muslim communities in the United States. Psychiatric Services, 56, 2-5. http://dx.doi.org/10.1176/appi.ps.56.2.202

Al-Krenawi, A. (2005). Mental health practice in Arab countries. Current Opinion in Psychiatry, 18, 560-564. http://dx.doi.org/10.1097/01.yco.0000179498.46182.8b

Al-Krenawi, A. \& Graham, J. R. (2000). Culturally sensitive social work practice with Arab clients in mental health settings. Health and Social Work, 25, 9-22. http:// dx.doi.org/10.1093/hsw/25.1.9

Aloud, N., \& Rathur, A. (2009). Factors affecting attitudes towards seeking and using formal mental health and psychological services among Arab Muslim populations. Journal of Muslim Mental Health, 4, 79-103. http://dx.doi. org/10.1080/15564900802487675

Anglin, D., Link, B., \& Phelan, J. (2006). Racial differences in stigmatizing attitudes toward people with mental illness. Psychiatric Services, 57, 857-862. http://dx.doi. org/10.1176/appi.ps.57.6.857

Amer, M. M., (2006). When multicultural worlds collide: Breaking down barriers to service use. Paper presented at the annual meeting of American Psychological Association. New Orleans.

Beatty, J. E., \& Kirby, S. L. (2006). Beyond the legal environment: How stigma influences invisible identity groups in the workplace. Employee Responsibilities and Rights Journal, 18(1), 29-44. http://dx.doi.org/10.1007/s10672-005-9003-6

Ciftci, A. (May, 1999). Communication in Family. ARTI Rehabilitation Services Annual Family Conference, Ankara, Turkey.

Ciftci, A., Shawahin, L., Reid-Marks, L., \& Ellison, Z. (2013). Campus Experience for Muslim Women Wearing \ijäb. Paper presented at the National Multicultural Summit, Houston, TX.

Cinnirella, M., \& Loewenthal, K. M. (1999). Religious and ethnic group influences on beliefs about mental illness: A qualitative interview study. British Journal of Medical Psychology, 72, 505-524. http://dx.doi.org/10.1348/000711299160202

Clair, J. A., Beatty, J., \& MacLean, T. (2005). Out of sight but not out of mind: Managing invisible social identities in the workplace. Academy of Management Review, 30, 78- 95. http://dx.doi.org/10.5465/AMR.2005.15281431

Coker, E. M. (2005). Selfhood and social distance: Toward a cultural understanding of psychiatric stigma in Egypt. Social Science \& Medicine, 61, 920-930. http://dx.doi. org/10.1016/j.socscimed.2005.01.009

Collins, P. H., (2000). Black feminist thought: Knowledge, consciousness, and the politics of empowerment (2nd ed.), New York, NY: Routledge.

Collins, P. H., (2007). Pushing the boundaries or business as usual? Race, class, and gender studies and sociological inquiry, in C. Calhoun (Ed.), Sociology in America: A History (pp. 572-604), Chicago, IL: University of Chicago Press.

Collins, P. Y., Elkington, K. S., Von Unger, H., Sweetland, A., Wright, E. R., \& Zybert, P. A. (2008). Relationship of stigma to HIV risk among women with mental illness. American Journal of Orthopsychiatry, 78, 498-506. http://dx.doi.org/10.1037/ a0014581

Collins, P. Y., von Unger, H., \& Armbrister, A. (2008). Church ladies, good girls, and locas: Stigma and the intersection of gender, ethnicity, mental illness, and sexual- 
ity in relation to HIV risk. Social Science \& Medicine, 67, 389-397. http://dx.doi. org/10.1016/j.socscimed.2008.03.013

Corrigan, P. W. (2004). How stigma interferes with mental health care. American Psychologist, 59, 614-625. http://dx.doi.org/10.1037/0003-066X.59.7.614

Corrigan, P. W. (2011). Best practices: Strategic stigma change (SSC): Five principles for social marketing campaigns to reduce stigma. Psychiatric Services, 62, 824-826. http://dx.doi.org/10.1176/appi.ps.62.8.824

Corrigan, P. W., \& Watson, A. C. (2002). The paradox of self-stigma and mental illness. Clinical Psychology: Science and Practice, 9, 35-53. http://dx.doi.org/10.1093/ clipsy.9.1.35

Corrigan, P.W., \& Watson, A.C. (2007). The stigma of psychiatric disorders and the gender, ethnicity, and education of the perceiver. Community Mental Health Journal, 43, 439-458. ?-328. http://dx.doi.org/10.1007/s10597-007-9084-9

Corrigan, P.W., Larson, J.E., \& Rusch, N. (2009). Self-stigma and the "why try" effect: impact on life goals and evidence-based practices. (2009). World Psychiatry, 8(2), 75-81.

Crabb, J., Stewart, R. C., Kokota, D., Masson, N., Chabunya, S., \& Krishnadas, R. (2012). Attitudes towards mental illness in Malawi: A cross-sectional survey. BMC Public Health, 12(1), 541. http://dx.doi.org/10.1186/1471-2458-12-541

DeShaw, P. (2006). Use of the emergency department by Somali immigrants and refugees. Minnesota Medicine, 89(8), 42-45.

Douki, S., Ben Zineb, S., Nacef, F., \& Halbreich, U. (2007). Women's mental health in the Muslim world: Cultural, religious, and social issues. Journal of Affective Disorders, 102(1), 177-189. http://dx.doi.org/10.1016/j.jad.2006.09.027

El-Islam, M. F. (2008). Arab culture and mental health care. Transcultural psychiatry, 45, 671-682. http://dx.doi.org/10.1177/1363461508100788

Erickson, C. D., \& Al-Timimi, N. R. (2001). Providing mental health services to Arab Americans: Recommendations and considerations. Cultural Diversity and Ethnic Minority Psychology, 7, 308-327. http://dx.doi.org/10.1037/1099-9809.7.4.308

Fung, K. M. T., Tsang, H. W. H., Corrigan, P. W., \& Lam, C. S. (2007). Measuring selfstigma of mental illness in China and its implications for recovery. International Journal of Social Psychiatry, 53, 408-418. http://dx.doi.org/10.1177/0020764007078342

Gary, F. A. (2005). Stigma: Barrier to mental health care among ethnic minorities. Issues in Mental Health Nursing, 26, 979-999. http://dx.doi.org/10.1080/01612840500280638

Goffman, E. (1963). Stigma: Notes on the Management of Spoiled Identity. New York: Simon and Schuster.

Hancock, A. M. (2007). When multiplication doesn't equal quick addition: Examining intersectionality as a research paradigm. Perspectives on Politics, 5(1), 63-79. http://dx.doi.org/10.1017/S1537592707070065

Hamdan, A. (2009). Mental health needs of Arab women. Health Care for Women International, 30, 595-613. http://dx.doi.org/10.1080/07399330902928808

Jamal, A. A. (2008). Race and Arab Americans before and after 9/11: From invisible citizens to visible subjects. Syracuse, N.Y.: Syracuse University Press.

Jasinskaja-Lahti, I., Liebkind, K., \& Perhoniemi, R. (2006). Perceived discrimination and well-being: A victim study of different immigrant groups. Journal of community \& applied social psychology, 16, 267-284. http://dx.doi.org/10.1002/casp.865

Joachim, G., \& Acorn, S. (2000). Living with chronic illness: The interface of stigma and normalization. Canadian Journal of Nursing Research, 32, 37-48. 
Jorm, A. F., \& Griffiths, K. M. (2008). The public's stigmatizing attitudes towards people with mental disorders: How important are biomedical conceptualizations? Acta Psychiatrica Scandinavica, 118, 315-321. http://dx.doi.org/10.1111/j.1600-0447.2008.01251.x

Keller, J. (2005). In genes we trust: The biological component of psychological essentialism and its relationship to mechanisms of motivated social cognition. Journal of Personality and Social Psychology, 88, 686-702. http://dx.doi.org/10.1037/00223514.88.4.686

Khan, Z. (2006). Attitudes toward counseling and alternative support among Muslims in Toledo, Ohio. Journal of Muslim Mental Health, 1, 21-42. http://dx.doi. org/10.1080/15564900600654278

Kung, W. W. (2003). The illness, stigma, culture, or immigration: Burdens on Chinese American caregivers of patients with schizophrenia. Families in Society, 84, 547557. http://dx.doi.org/10.1606/1044-3894.140

Lam, C. S., et al. (2010). Chinese lay theory and mental illness stigma: Implications for research and practices. Journal of Rehabilitation, 76, 35-40.

Lauber, C., \& Rössler, W. (2007). Stigma towards people with mental illness in developing countries in Asia. International Review of Psychiatry, 19, 157-178. http:// dx.doi.org/10.1080/09540260701278903

Link, B. G., Phelan, J. C., Bresnahan, M., Stueve, A., \& Pescosolido, B. A. (1999). Public conceptions of mental illness: Labels, causes, dangerousness, and social distance. American Journal of Public Health, 89, 1328-1333. http://dx.doi.org/10.2105/ AJPH.89.9.1328

Loya, F., Reddy, R., \& Hinshaw, S. P. (2010). Mental illness stigma as a mediator of differences in Caucasian and South Asian college students' attitudes toward psychological counseling. Journal of Counseling Psychology, 57, 484-490. http://dx.doi. org/10.1037/a0021113

Mak, W. W., \& Cheung, R. Y. (2008). Affiliate stigma among caregivers of people with intellectual disability or mental illness. Journal of Applied Research in Intellectual Disabilities, 21, 532-545. http://dx.doi.org/10.1111/j.1468-3148.2008.00426.x

Marrow, J., \& Luhrmann, T. M. (2012). The zone of social abandonment in cultural geography: On the street in the United States, inside the family in India. Culture, medicine and psychiatry, 1-21.

Nabolsi, M. M., \& Carson, A. M. (2011). Spirituality, illness, and personal responsibility: The experience of Jordanian Muslim men with coronary artery disease. Scandinavian Journal of Caring Sciences, 25, 716-724. http://dx.doi.org/10.1111/j.1471-6712.2011.00882.x

Ng, C. H. (1997). The stigma of mental illness in Asian cultures. Australian and New Zealand Journal of Psychiatry, 31, 382-390. http://dx.doi. org/10.3109/00048679709073848

Padela, A. I., Killawi, A., Forman, J., DeMonner, S., \& Heisler, M. (2012). American Muslim perceptions of healing key agents in healing, and their roles. Qualitative Health Research, 22, 846-858. http://dx.doi.org/10.1177/1049732312438969

Pew Research Center's Forum on Religion and Public Life. (2011). The Future of the Global Muslim Population. Retrieved from http://www.pewforum.org/The-Futureof-the-Global-Muslim-Population.aspx

Phelan, J. C. (2005). Geneticization of deviant behavior and consequences for stigma: The case of mental illness. Journal of Health and Social Behavior, 46, 307-322. http://dx.doi.org/10.1177/002214650504600401 
Phelan, J. C., Bromet, E. J., \& Link, B. G. (1998). Psychiatric illness and family stigma. Schizophrenia Bulletin, 24(1), 115-126. http://dx.doi.org/10.1093/oxfordjournals. schbul.a033304

Rao, D., Feinglass, J., \& Corrigan, P. (2007). Racial and ethnic disparities in mental illness stigma. Journal of Nervous and Mental Disease, 195, 1020-1023. http://dx.doi. org/10.1097/NMD.0b013e31815c046e

Rassool, G. H. (2000). The crescent and Islam: Healing, nursing, and the spiritual dimension: Some considerations towards an understanding of the Islamic perspectives on caring. Journal of Advanced Nursing, 32, 1476-1484. http://dx.doi. org/10.1046/j.1365-2648.2000.01614.x

Rippy, A. E., \& Newman, E. (2006). Perceived religious discrimination and its relationship to anxiety and paranoia among Muslim Americans. Journal of Muslim Mental Health, 1, 5-20. http://dx.doi.org/10.1080/15564900600654351

Rüsch, N., Corrigan, P. W., Wassel, A., Michaels, P., Olschewski, M., Wilkniss, S., \& Batia, K. (2009). In-group perception and responses to stigma among persons with mental illness. Acta Psychiatrica Scandinavia, 12, 320. http://dx.doi.org/10.1111/ j.1600-0447.2009.01403.x

Rüsch, N., Todd, A. R., Bodenhausen, G. V., \& Corrigan, P. W. (2010). Biogenetic models of psychopathology, implicit guilt, and mental illness stigma. Psychiatry research, 179, 328-332. http://dx.doi.org/10.1016/j.psychres.2009.09.010

Shah, S. M., Ayash, C., Pharaon, N. A., \& Gany, F. M. (2008). Arab American immigrants in New York: Health care and cancer knowledge, attitudes, and beliefs. Journal of Immigrant and Minority Health, 10, 429-436. http://dx.doi.org/10.1007/ s10903-007-9106-2

Schomerus, G., Matschinger, H., \& Angermeyer, M. C. (2013). Continuum beliefs and stigmatizing attitudes towards persons with schizophrenia, depression and alcohol dependence. Psychiatry Research. http://dx.doi.org/10.1016/j.psychres.2013.02.006

Schomerus, G. G., Schwahn, C. C., Holzinger, A. A., Corrigan, P. W., Grabe, H. J., Carta, M. G., \& Angermeyer, M. C. (2012). Evolution of public attitudes about mental illness: A systematic review and meta-analysis. Acta Psychiatrica Scandinavica, 125, 440-452. http://dx.doi.org/10.1111/j.1600-0447.2012.01826.x

Shibre, T., Negash, A., Kullgren, G., Kebede, D., Alem, A., Fekadu, A., \& Jacobsson, L. (2001). Perception of stigma among family members of individuals with schizophrenia and major affective disorders in rural Ethiopia. Social Psychiatry and Psychiatric Epidemiology, 36, 299-303. http://dx.doi.org/10.1007/s001270170048

Stefan, S. (2000). Delusions of rights: Americans with psychiatric disabilities, employment discrimination, and the Americans with Disabilities Act. Alabama Law Review, 52, 271-275.

Soheilian, S. S., \& Inman, A. G. (2009). Middle Eastern Americans: The effects of stigma on attitudes toward counseling. Journal of Muslim Mental Health, 4, 139-158. http://dx.doi.org/10.1080/15564900903245766

Tabassum, R., Macaskill, A., \& Ahmad, I. (2000). Attitudes towards mental health in an urban Pakistani community in the United Kingdom. International Journal of Social Psychiatry, 46, 170-181. http://dx.doi.org/10.1177/002076400004600303

Tal, A., Roe, D., Corrigan, P. W. (2007). Mental illness stigma in the Israeli context: Deliberation and suggestions. International Journal of Social Psychiatry, 53, 547-563. http://dx.doi.org/10.1177/0020764007082346

Vanaleesin, S., Suttharangsee, W., \& Hatthakit, U. (2010). Cultural aspects of care for 
Muslim schizophrenic patients: An ethnonursing study. Songklanagarind Medical Journal, 25, 361-370.

Van Oort, F. V., van der Ende J., Crijnen, A. A., Verhulst, F. C., Mackenbach, J. P., \& Joung, I. (2007). Ethnic disparities in mental health and educational attainment: Comparing migrant and native children. International Journal of Social Psychiatry, 53, 514-525. http://dx.doi.org/10.1177/0020764007078355

Vogel, D. L., Armstrong, P. I., Tsai, P. C., Wade, N. G., Hammer, J. H., Efstathiou, G., \& Topkaya, N. (2013). Cross-cultural validity of the Self-Stigma of Seeking Help (SSOSH) Scale: Examination across six nations. Journal of Counseling Psychology. http://dx.doi.org/10.1037/a0032055

Wesselmann, E. D., \& Graziano, W. G. (2010). Sinful and/or possessed? Religious beliefs and mental illness stigma. Journal of Social and Clinical Psychology, 29, 402437. http://dx.doi.org/10.1521/jscp.2010.29.4.402

Whidden, M. J. (2000). Unequal justice: Arabs in America and United States antiterrorism legislation. Fordham Law Review, 69, 2825.

Wirth, J. H., \& Bodenhausen, G. V. (2009). The role of gender in mental-illness stigma: A national experiment. Psychological Science, 20, 169-173. http://dx.doi. org/10.1111/j.1467-9280.2009.02282.x

Yang, L. H., Kleinman, A., Link, B. G., Phelan, J. C., Lee, S., \& Good, B. (2007). Culture and stigma: Adding moral experience to stigma theory. Social Science \& Medicine, 64, 1524-1535. http://dx.doi.org/10.1016/j.socscimed.2006.11.013

Yang, L., \& Pearson, V. J. (2002). Understanding families in their own context: Schizophrenia and structural family therapy in Beijing. Journal of Family Therapy, 24, 233-257. http://dx.doi.org/10.1111/1467-6427.00214

Youssef, J. \& Deane, F. P. (2006). Factors influencing mental-health help-seeking in Arabic-speaking communities in Sydney, Australia. Mental Health, Religion \& Culture, 9, 43-66. http://dx.doi.org/10.1080/13674670512331335686

Ypinazar, V. A., \& Margolis, S. A. (2006). Delivering culturally sensitive care: The perceptions of older Arabian gulf Arabs concerning religion, health, and disease. Qualitative Health Research, 16, 773-787. http://dx.doi.org/10.1177/1049732306288469 